\title{
Assessment of safety distance between components of nuclear plant and study of the vulnerabiliy of the damage caused by an explosion
}

\author{
Aminu Ismaila ${ }^{1,3}$, Rafiziana Md Kasmani ${ }^{2 *}$, Koh Meng-Hock ${ }^{1}$, and Ahmad Termizi Ramli ${ }^{1}$ \\ ${ }^{1}$ Physics Department, Universiti Teknologi Malaysia, 81310 Skudai, Johor, Malaysia \\ ${ }^{2}$ Energy Engineering Department Universiti Teknologi Malaysia, 81310 Skudai, Johor, Malaysia \\ ${ }^{3}$ Department of Physics, Ahmadu Bello University Zaria, Nigeria
}

\begin{abstract}
This paper deals with the assessment of external explosion, resulting from accidental release of jet fuel from the large commercial airliner in the nuclear power plant (NPP). The study used three widely prediction methods such as Trinitrotoluene (TNT), multi energy (TNO) and Baker-strehow (BST) to determine the unconfined vapour cloud explosion (UVCE) overpressure within the distances of 100-1400 m from the first impact location. The containment building was taken as the reference position. The fatalities of persons and damage of structures was estimated using probit methodology. Analysis of the results shows that both reactor building and control-room will be highly damaged with risk consequences and probability, depending on the assumed position of the crash. The structures at the radial distance of $600 \mathrm{~m}$ may suffer major structural damage with probability ranging from 25 to $100 \%$. The minor structural damage was observed throughout the bounds of the plant complex. The people working within $250 \mathrm{~m}$ radius may get affected with different fatality ranging from 28 to $100 \%$. The findings of this study is valuable to evaluate the safety improvement needed on the NPP site and on the risk and consequences associated with the hydrocarbon fuel release/fires due to external hazards.
\end{abstract}

\section{Introduction}

External hazards (e.g. aircraft impact, flooding and earthquake) can be a significant contributor to the risk in case of nuclear power plant (NPP) operation and can pose serious hazards to the public and environment due to release of hazardous radiation resulting from fire-induced failures of important plant safety systems [1-3]. It may challenge the available emergency services and affect the mechanism for a safe reactor shutdown and this could led to unsafe condition with the potential to cause for reactor core damage. The risk assessment has been the conventional method for assessing the risk and consequences of fire or any

\footnotetext{
*orresponding author: rafiziana@utm.my
} 
form of explosion in the NPP. In the risk assessment method, the consequences of possible accidents and disasters are estimated. The safety standards issued by the regulatory agencies are based on the outcome of fire risk analysis. It appears that the consequences from the occurrence of 'incredible events' were not fully addressed in in the probabilistic risk assessment. This has been strongly underlined by the Fukushima Daiichi NPP incident of March 11, 2011 and World Trade Centre (WTC) aircraft attack of September 11, 2001 [4]. For an accident involving aircraft impacting a nuclear structure, consideration should be given to the hazards of impact loading of the aircraft and jet fuel initiated fires after the incident. These requirements are contained in the IAEA documents (NS-G-1.5 and NS-G$3.1)$.

The factors which determine the severity of aircraft induced explosion include size and speed of the plane, pulse duration, interaction of subsystems, quantity of fuel involved in the explosion, ignition location and time, turbulence level in the plant, scale of the plant, location and shape of obstacles, blockage ratio, early response to the fight fire and availability of firefighting equipment $[5,6]$. Of particular interest to this article is the congestion level and location of the obstacles. These are directly related to spatial arrangement of structures and may have a strong influence on the evolution of fireball, pressure build-up and propagation. Therefore, assessment of safety distances between important NPP components for the postulated aircraft incident is the main focus of this study.

This work aims to measure the explosion overpressure and pulse duration that may be experienced by the reactor containment and control-room walls for the hypothetical aircraft incident. Three empirical models (TNT, TNO and BST) were used to determine the overpressure and pulse duration at a given distance from the point of explosion. Those data (overpressure and pulse duration) were used to assess safety distances between building components within the NPP vicinity. The vulnerability of persons and structures were assessed using probit methodology. The subsequent pool fire and fireball effects were not considered in this paper.

\section{Theory}

The overpressures generated due to UVCE and explosion's effects are primarily influenced by the degree of confinement, weather conditions, quantity and flammability of fuel as well as source and strength of ignition [7]. The assumptions used in developing the empirical models for the UVCE assessment are generally based on these four parameters. This research work uses the most widely empirical predictive models to estimate the consequences of the blastwave produced by UVCE as a function of distance. A brief description of the models are provided in the following sections.

\subsection{Equivalent TNT mass Method (TNT)}

This empirical method is based on the assumption that the entire flammable volume of cloud takes part in the explosion and that the explosion is centred in a single location [8]. The explosive energy of TNT served as the benchmark against explosive power of other materials [9]. In the method, the explosive energy of UVCE is expressed as an equivalent mass of tri-nitrotoluene (TNT) that would produce the same explosive energy [10]. In other words, the destruction arises from the mass of TNT is considered to be the same to that of flammable substance under investigation [7]. The explosive potential is primarily 
determined by the amount of fuel released. The equivalent-charge-mass of TNT is calculated as in Equation 1.

$$
M_{T N T}=\frac{f_{E} \Delta H_{c} M_{f}}{\Delta H_{T N T}}
$$

where $\mathrm{M}_{\mathrm{f}}(\mathrm{kg})$ is the mass of fuel that involved in the explosion, $\Delta \mathrm{Hc}(\mathrm{J} / \mathrm{kg})$ is heat of combustion of the fuel, $\Delta \mathrm{H}_{\mathrm{TNT}}(\mathrm{J} / \mathrm{kg})$ is heat of combustion of TNT $(4,760 \mathrm{~kJ} / \mathrm{kg})$, and $f_{E}$ is the TNT efficiency factor which depend on the degree of confinement in the area. A value of $10 \%$ was used in this study.

For TNT calculation, the Hopkinson-Cranz cube-root scaled distance is given as

$$
Z=\frac{x}{M_{T N T} \frac{1}{3}}
$$

where $\mathrm{Z}$ is the scaled distance $\left(\mathrm{m} \mathrm{kg}^{-1 / 3}\right), \mathrm{M}_{\text {TNT }}$ is the TNT mass $(\mathrm{kg})$ equivalent and is the distance $(\mathrm{m})$ from the centre of explosion. The corresponding value of overpressure of the shock wave resulting from the UVCE for any given scale distance can also be computed using Equation 3 [10].

$$
P_{s}=\frac{808\left(1+\left(\frac{Z}{4.5}\right)^{2}\right)}{\sqrt{1+\left(\frac{Z}{0.048}\right)^{2}} \sqrt{1+\left(\frac{Z}{0.32}\right)^{2}} \sqrt{1+\left(\frac{Z}{1.35}\right)^{2}}}
$$

The TNT method is simple and easier to use. It is also attractive if the overall damage potential is the only concern particularly for estimating far field damage as reported. However, the biggest problems with this method is that it is not applicable to small distances and overpressures greater than 1 bar. The local pressure evolved in case of TNT is much higher than that of flammable gas explosion waves which travels to a larger distance [8]. A typical error of $20-30 \%$ for the explosive performance between TNT and other higher explosives have been reported [11]. Therefore, this method does not estimate overpressure correctly for a far field regions as in most cases it is being over-predicted. Consequently, the predicted blast modelling results could be said to be statistically unreliable. Despite of the drawbacks due to its simplified assumptions, the TNT model is still widely applied in the prediction of blast overpressure at a particular at a particular point of interest from the explosion centre.

\subsection{TNO Multi Energy Method (TNO)}

This method is based on the basic assumption that detonation can only take place in the obstructed region and could be ruled out in the unconfined parts of the region. The congested regions will contribute to a higher strength of explosion blast. Unobstructed parts of the cloud will slowly burn, without much contribution to the strength of the blast [1012]. This assumption is supported by vast experimental data $[13,14]$. The energy, E (MJ) released by the explosion and Sachs-scaled distance, $r$ ' (dimensionless) are given by Equation 4 and 5 respectively. 


$$
E=\left(V\left[\Delta H_{c} * \rho * \frac{1}{15.6}\right]\right)
$$

where, $\Delta H \mathrm{c}$ is the heat of combustion of explosive (43 MJ/kg), $V$ is the cloud volume, $\rho$ is the density $\left(810 \mathrm{~kg} \mathrm{~m}^{-3}\right)$ and the factor $\left(\frac{1}{15.6}\right)$ is the stoichiometry of the reaction (ratio of fuel: air).

$$
r^{\prime}=x\left(\frac{E}{P_{a}}\right)^{-\frac{1}{3}}
$$

where, $x$ is the distance from the centre of explosion, $\mathrm{E}$ is the energy released during the explosion, and $\mathrm{P}_{\mathrm{a}}$ is the ambient pressure $(0.1 \mathrm{MPa})$. A step by step on using this method is described [12].

With the equation 4 and 5, the blast overpressure P (MPa) can be calculated as follows:

$$
P=P_{s}^{\prime} * P_{a}
$$

where $P_{s}^{\prime}$ the Sachs-scaled overpressure (dimensionless) and $\mathrm{Pa}$ is the ambient atmospheric pressure ( MPa). The Sachs-scaled overpressure is estimated from the curves consisting of scaled overpressure versus dimensionless scaled distance.

The time duration of positive phase $t_{p}(s)$ is given by the equation:

$$
t_{p}=\left(t_{p}^{\prime} / C_{s}\right)\left(E / P_{a}\right)^{\frac{1}{3}}
$$

where $t_{p}^{\prime}$ is the Sachs-scaled pulse duration obtained from the curve consists of positive pulse duration versus scaled distance shown in the researches by [12, 13], $\mathrm{C}_{\mathrm{s}}$ is the velocity of sound in air $\left(340 \mathrm{~m} \mathrm{~s}^{-1}\right), \mathrm{E}$ is the energy released $(\mathrm{MJ})$ and $\mathrm{P}_{\mathrm{a}}$ is the ambient pressure $(0.1 \mathrm{MPa})$.

It was observed in various studies that empirical results from the TNO multi energy method are generally much closer to the experimental data based upon the most common damages that occur from explosion $[8,14]$. This method was use for vulnerability calculations.

The assumption of 54 tonne of jet fuel will produce a vapour cloud of $1030.85 \mathrm{~m}^{3}$. The radius, $R(\mathrm{~m})$ of the cloud being considered as a hemisphere is calculated to be 7.895 $\mathrm{m}$. The volume of the congested region $(120 * 60 * 20 \mathrm{~m})$ is found to be $144,000 \mathrm{~m}^{3}$. This will give an empty space of $143,933.92 \mathrm{~m}^{3}$ for the dispersion of the cloud. The assumption that $30 \%$ of the fuel capacity to be involved in the explosion will make this part to generate blast of high strength (i.e, higher than 7). A higher strength explosion blast of 10 is used in this scenario. The energy E release by the explosion is calculated as 2301566.4 MJ 
(2301.5664 GJ). The energy released during explosion is very close to resultant total fuel energy adds up (54 tonne x 43 GJtonne $^{-1}=2322$ GJ) showing that there is energy conservation.

\subsection{Baker-Strehlow-Tang Method (BST)}

This technique is similar to multi-energy method only differs in their assumptions. The BST model is based on the assumption that the strength of the blast wave is directly related to the maximum flame speed attained within the cloud. Therefore, the important parameter in the selection of the intensity of the explosion blast in this method is the flame propagation speed [15]. The determination of explosion energy follows the recommendations in the Multi-Energy method. The intensity of UVCE is determined by the following factors: (i) degree of confinement (ii) density of the obstacles (iii) the reactivity of the fuel and (iv) the way the flame front propagates [13]. The procedure from TNO method was adopted in determining the vapour cloud dimension and energy released during explosion. The scaled overpressure is calculated from the curve consisting of scaled overpressure as a function of scaled distance, with the flame speed (in form of March number, Mf) as a parameter described in $[11,12]$. The reactivity of jet fuel is higher and blockage ratio of the plant in this scenario is considered to be higher than $40 \%$. A $2 \mathrm{D}$ flame expansion at a speed of 1.77 is considered in this study.

\section{The Scenario}

\subsection{Description of the Scenario}

A generic site plan of a "hypothetical nuclear power plant" is shown in Figure 1. The plant dimensions is $1 \mathrm{~km} \times 1 \mathrm{~km}$. A reinforced concrete reactor containment composed of a circular base slab, an upright cylindrical walls and torispherical dome is placed between control room and stack. The thickness of inner containment is $1 \mathrm{~m}$ and outer containment wall (as well as dome) is $1.2 \mathrm{~m}$ in line with IAEA guideline [16]. The inner containment is to provide biological shielding while the outer containment is to protect the reactor from external threats. The height of outer containment building is $62 \mathrm{~m}$ and $42 \mathrm{~m}$ inner radius. The control building that houses the main control room is located on the central location as the hub of the plant operating staff's activities. The congested area consisting of control building, service building, tank storage and condensate storage tank has an average dimension of $120 \mathrm{~m} \times 60 \mathrm{~m} \times 20 \mathrm{~m}$. The arrangement of the building structures is shown in Figure 1.

A hypothetical scenario of aircraft impacting a nuclear reactor containment is considered. About 54 tonne of jet fuel (kerosene equivalent) is assumed to involve in the explosion immediately after the incident. The site layout and blast radius after explosion is shown in Figure 1. 


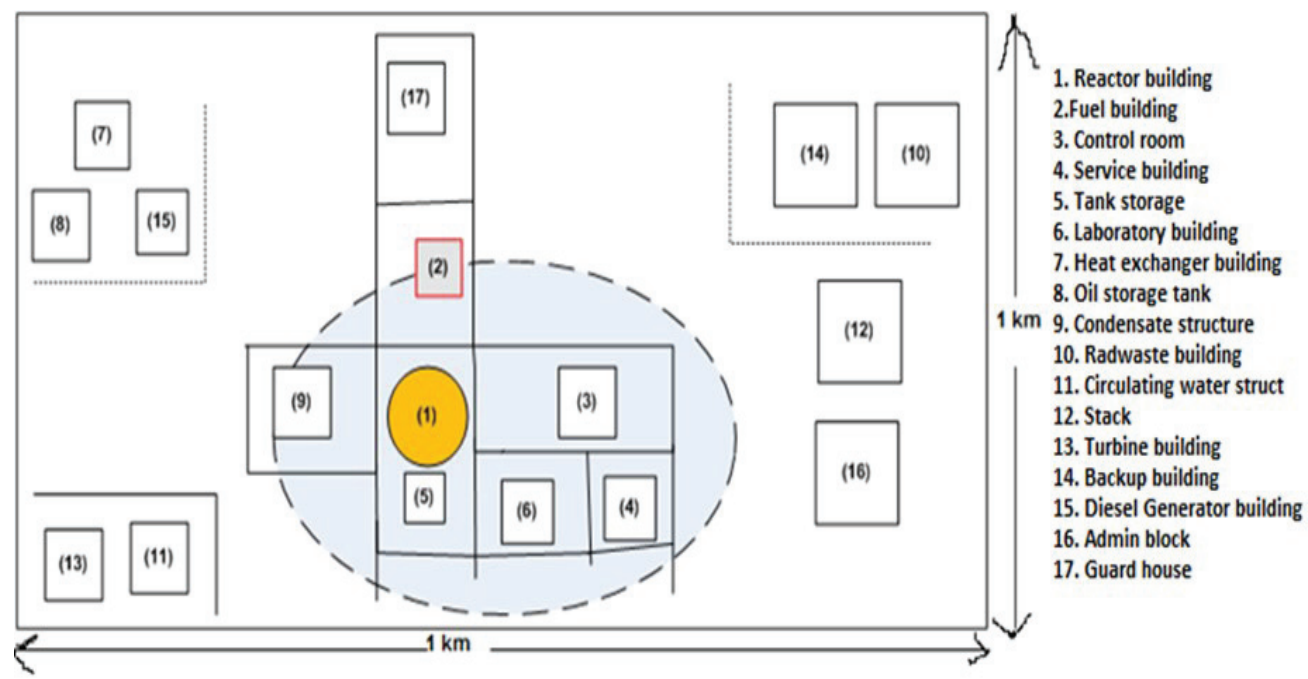

Fig. 1: The plant layout

\subsection{Vulnerability Estimation}

The vulnerability of individuals and structures to the effects of explosion generally follows probabilistic approach in form of probit (probability unit) methodology. The vulnerability estimates gives an idea of the number of persons who can possibly be affected by explosion in terms of important injuries or casualities. The injuries are that by head impact, eardrum rupture, body displacement or death from lung damage .It also gives an idea on the damage level experienced by the srtuctures as minor or major. It is of interest to note that the probit unit represent an approximation for the probability of surval after impact of the body part. In this study, probit equation developed by $[17,18]$ was used to evaluate the direct effects of explosion on structures. The structural damage equation is given by

$$
P_{r}=5.0-0.26 \log _{e} V
$$

where $\mathrm{V}$ is the is the measure of the intensity of the damage-causative factor and varies according to the damage intensity.

For major structural damage:

$$
V=\left(\frac{17,500}{p_{s}}\right)^{8.4}+\left(\frac{290}{i_{s}}\right)^{9.3}
$$

and for minor structural damage:

$$
V=\left(\frac{4,600}{P_{s}}\right)^{3.9}+\left(\frac{110}{i_{s}}\right)^{5.0}
$$


where $i_{s}$ is the impulse of the shock wave $\left(\frac{1}{2} p_{s} t_{p}\right), \mathrm{P}_{\mathrm{s}}$ is the peak or maximum overpressure $(\mathrm{Pa})$ and $t_{p}$ is the positive phase duration $(\mathrm{s})$.

Several probit equations which estimate the fatality of persons from head impact, eardrum fracture, and death from possible lung damage and whole-body displacement have been proposed. An equation for estimating lung damage and death from explosion has been proposed by [18] and is given as

$$
P_{r}=5.0-5.74 \log S
$$

$$
\text { where } S=\frac{4.2}{\bar{P}}+\frac{1.3}{\bar{l}}
$$

The parameters $\bar{P}\left(\frac{p}{p_{a}}\right)$ in equation (12) is the scale overpressure on person depending on orientation and $\bar{l}=\left(\frac{i}{m^{\frac{1}{3}} \sqrt{p_{a}}}\right)$ is the scale impulse which is a function of mass, $\mathrm{m}(\mathrm{kg})$. A vertical orientation for a $75 \mathrm{~kg}$ mass of an adult men is used in this study.

The correlation equation for estimating eardrum damage due to explosion is given by Equation 13 [18].

$$
P_{r}=-12.6-1.524 \log _{e} P_{s}
$$

And for head impact is given by Equation 13 [18].

$$
\begin{aligned}
& P_{r}=5.0-8.49 \log _{e} S \\
& \text { where } S=\frac{2.43 * 10^{3}}{P_{S}}+\frac{4 * 10^{9}}{P_{s} i_{s}}
\end{aligned}
$$

A correlation equation for death due to whole body displacement given as follows $[18,19]$.

$$
\begin{aligned}
& P_{r}=5.0-2.44 \log _{e} S \\
& \text { where } S=\frac{7.38 * 10^{3}}{P_{s}}+\frac{1.3 * 10^{9}}{P_{s} i_{s}}
\end{aligned}
$$




\section{Results and Discussion}

\subsection{Variation of overpressure with distance}

Section 3.48 of the IAEA safety standard [20] elaborates that hazards due to chemical explosions should be perform on the site and shall be expresses in terms of overpressure and toxicity (if applicable) taken into account the effect of distance. The site should be consider unsuitable if the assessment of such external induced event could not meet the acceptable safety criteria or practicable solutions. The premise is that the effects of overpressure decreases with the increasing distances and vice versa. Therefore, a reasonable physical separation between structural components of the NPP should be provided at a location where the chemical explosion is envisage. A graph of overpressure against distance provides values of overpressures corresponding to a given distance and hence gives an idea of the degree of damage to structural components as a function of distance to an explosion.

The functional relationship between overpressure and distance from the explosion centre is presented in Figure 2. Analysis of the results show that there is higher blast pressure and long positive phase duration at a distance less than $700 \mathrm{~m}$ from the blast starting point. The damage corresponding to these overpressure levels are considered unbearable for most building structures. About 50 to $75 \%$ of all outer walls could be heavily damaged by the higher overpressure within these distances. The TNO method predicts higher overpressure as compared to other two methods at the same distances. However, the data for the TNO and BST are somewhat comparable for most data points. The main basic difference for the two models occur only at some few points as shown in the inside graph of figure 2 . The TNT method gives the lower values in the data points. The findings of this study agrees closely with that of (Soman and Sundararaj, 2012). However, in the study by (Lobato et al., 2006), it was observed that TNT model predicts higher values of overpressure in contradiction to our findings. The present authors are on the opinion that the variation in the results for the two models may be attributed to differences in the assumptions and scenario used. It was noted that the overpressure values obtained by TNO multi energy method are much closer to the experimental values based upon the damage could occur from explosion reported by (Marc and Konstantinos, 2010). Therefore, values of explosion overpressure obtained on the basis of multi energy approach were used for vulnerability estimation.

In the earlier study [6], it was observed that the structures at a separation distance of $600 \mathrm{~m}$ may likely suffer total destruction due to extremely higher overpressure generated from the explosion. At a distance of $800 \mathrm{~m}$, the blast overpressure is 0.08 bar while at 1000 $\mathrm{m}$, it was 0.07 bar. These values are considered unsafe as reported in the experimental results by [21-23]. They claimed that 0.068 bar could cause partial demolition of a typical brick buildings, which become uninhabitable. In other words, about $25 \%$ of all walls have failed and serious damage to the load carrying elements occurred. Therefore, taking into account our scenario whereby other building auxiliaries such as laboratory, tank storage, service building and control room are positioned at a distance below $800 \mathrm{~m}$ from the containment, it could be said that the structures within the radial distance of $1 \mathrm{~km}$ are not safe. When TNO method is applied to the Buncefied and Sitapura explosion incidents [24, 25], which have assumed the volume blockage ratio of $4 \%$, it estimated that the overpressure to be greater than 20 bar at a distance of $300 \mathrm{~m}, 0.09$ bar at a distance of $2 \mathrm{~km}$ and window break up to $8 \mathrm{~km}$ from the site. For a safety consideration, the overpressure received by the target element should be less than 0.02 bar. This could only lead to a limited minor damage like glass breakage or scabbing of the concrete structure. 
Accordingly, at a distance of $1300 \mathrm{~m}$, the overpressure estimated was $0.05 \mathrm{bar}$. This value is within the range considered to cause minor structural damage. Hence, this could not cause much safety concern when considered the safety measures in a typical NPP. On considering the engineering design of the reactor containment (reinforced concrete structure of thickness $>1 \mathrm{~m}$ ), the authors are on the opinion that collapse could not likely happen due to that postulated overpressure. However, other building auxiliaries may strongly damage. Therefore, the consequences will be determined by the failure of the safety components within the building and its interaction to other safety systems in the reactor building. This work did not address on what safety component of the plant will be affected by the explosion or fireball and how the failure of one safety system may affect the plant operation. This aspect would be treated by the probabilistic safety analysis. The primary concern of this article is to verify on what should be the minimum safety distance between building structures for a postulated aircraft incident in the NPP vicinity.

Another important safety concern in this scenario is the longer pulse duration as it has direct relationship to blast pressure impulse of the shock wave. At a distance of $100 \mathrm{~m}$ from the containment, the pulse duration was $126.96 \mathrm{~ms}$ and this translates to a detonation speed of $788 \mathrm{~ms}^{-1}$. Taking into account our scenario, the most important to be taking into consideration is the control room which served as the hub for the plant operating personals situated close to the containment. The explosion overpressure at this position may cause serious damage to this building thereby the manual/automatic control systems would lose their functions. It is therefore appropriate to improved positioning and safety measures of the control building within the bounds of the complex. In this case, the positioning should be at least $1300 \mathrm{~m}$ from the containment.

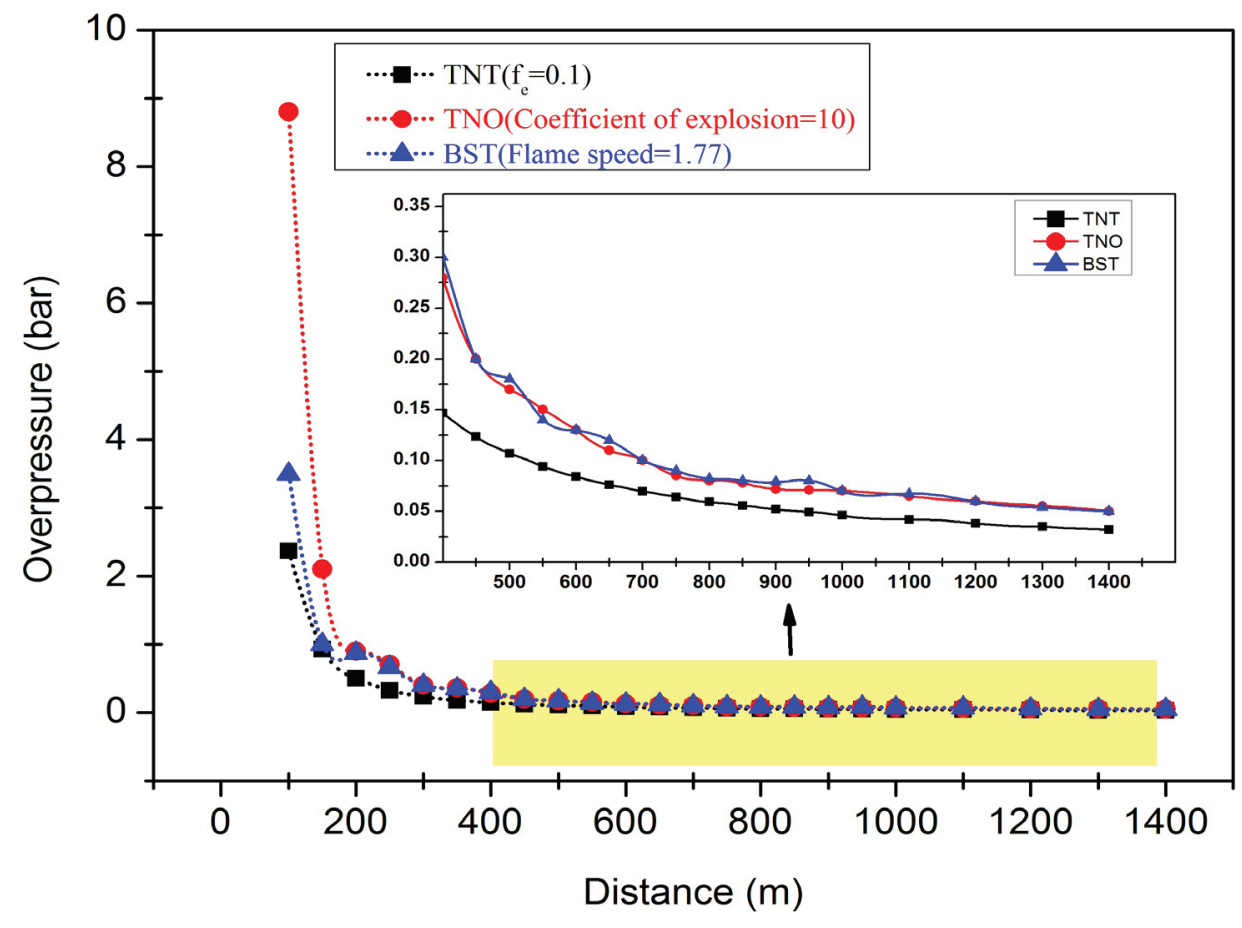

Fig. 2: Overpressure vs distance 


\subsection{Major and Minor Structural Damage}

A major damages are such a level of damage that caused total destruction of buildings which can no longer be restored or useable. By heavy damage, more than $75 \%$ of all outer walls have collapsed or majorly damaged and a number of load bearing structural elements have failed and structure has partially collapsed [18]. In case of minor damage, the peak overpressure in the incident wave is expected to cause failure of doors and windows, and that minor crack formation will appear in the load- carrying elements and in the outer walls. Also roofs, ceilings, glass panels and wall covering will be partially destroyed.

Figure 3 presents the percentage of measure and minor structural damage as a function of distance computed using Eq. 8. The vulnerability estimates show that at a distance of $800 \mathrm{~m}$, the probability of major damage to structures is $4.5 \%$. However, it is $46 \%$ at a distance of $500 \mathrm{~m}$. Therefore, from the safety point of view, the safety distance from the containment should not be less than $800 \mathrm{~m}$ where the probability of major structural damage is less than 5\%. Accordingly, the minor structural damage is higher up to a distance of $1000 \mathrm{~m}$ with a probability of $66 \%$. This analysis is in agreement with the result obtained by [7] which revealed that a minimum of $1 \mathrm{~km}$ safety distance (European Norm) should be considered for higher hazards sites similar to Buncefield. Though, the focus of this article is the assessment of vapour cloud explosion in the NPP site, our analysis showed that the recommended safety distance for hydrocarbon fuels storage depot could also be applied to the NPP site particularly if the blast effect is of prime interest. This assertion is applicable only if the release is less than 55 tonnes. For such worst case scenarios where more than 90 tonnes of jet fuel involved in the explosion, the effects can be reach up to $2 \mathrm{~km}$. In case of Buncefied incident, the effect (windows broken) from overpressure ( $>20$ bar) was observed up to $8 \mathrm{~km}$ away [24, 25].

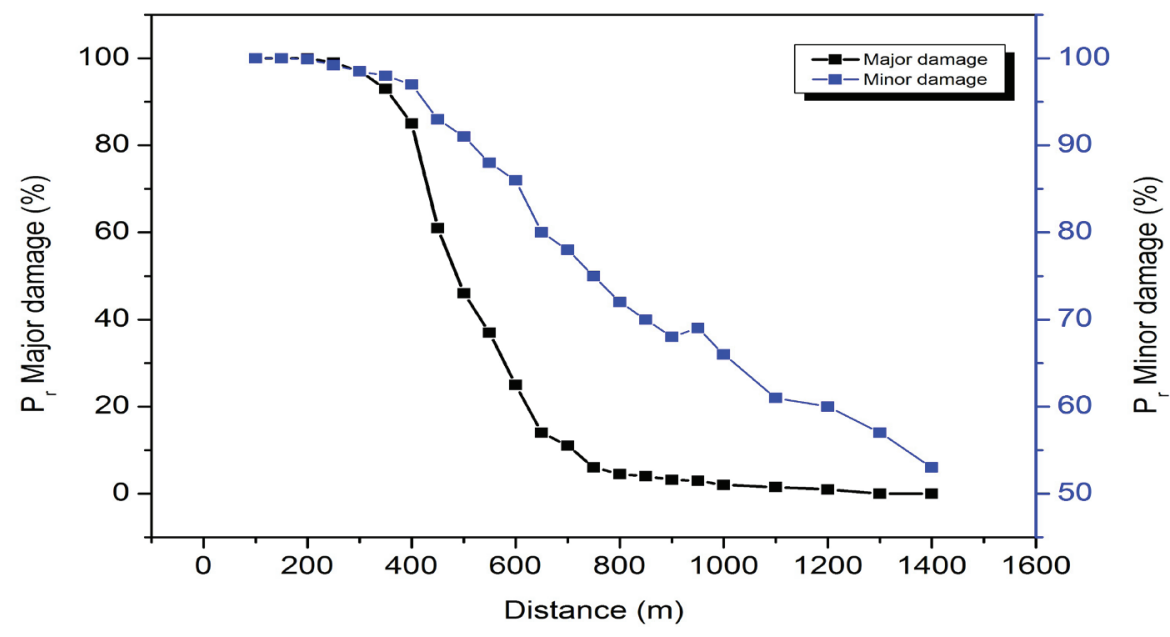

Fig. 3: Major and minor structural damage

\subsection{Estimation of Vulnerability of persons}

Figure 4 shows the effect of explosion on people for our scenario. For the probability of death due to eardrum rupture, the percentage fatality is calculated as $100 \%$ at a distance of $100 \mathrm{~m}$ whereas it is $7 \%$ at a location of $300 \mathrm{~m}$. For head impact, the percentage fatality is 
$100 \%$ at a distance below $230 \mathrm{~m}$ whereas is zero at a distance greater than $300 \mathrm{~m}$. The percentage fatality due to whole body displacement is estimated as $100 \%$ at a distance of $100 \mathrm{~m}$ but $3 \%$ at $200 \mathrm{~m}$, suggesting that there would be no survival for distance below 100 $\mathrm{m}$. The percentage fatality is zero for distances above $250 \mathrm{~m}$. For death due to lung damage, the percentage fertility is estimated as $100 \%$ at a distance of $350 \mathrm{~m}$ and above from the centre of explosion but it is zero at $150 \mathrm{~m}$ distance. This is quite inconsistent result as the lower distances should experience greater damage. This peculiar condition might be explained as follows; the threshold of lung hemorrhage is 0.68 bar and based on Figure 1, at distance of $200 \mathrm{~m}$, the overpressure is $\sim 0.7$ bar. The personnel might be escaping themselves once the alarmed went off, resulting to fatality of $100 \%$ at distance of $300 \mathrm{~m}$ as the overpressure exceeds the threshold.

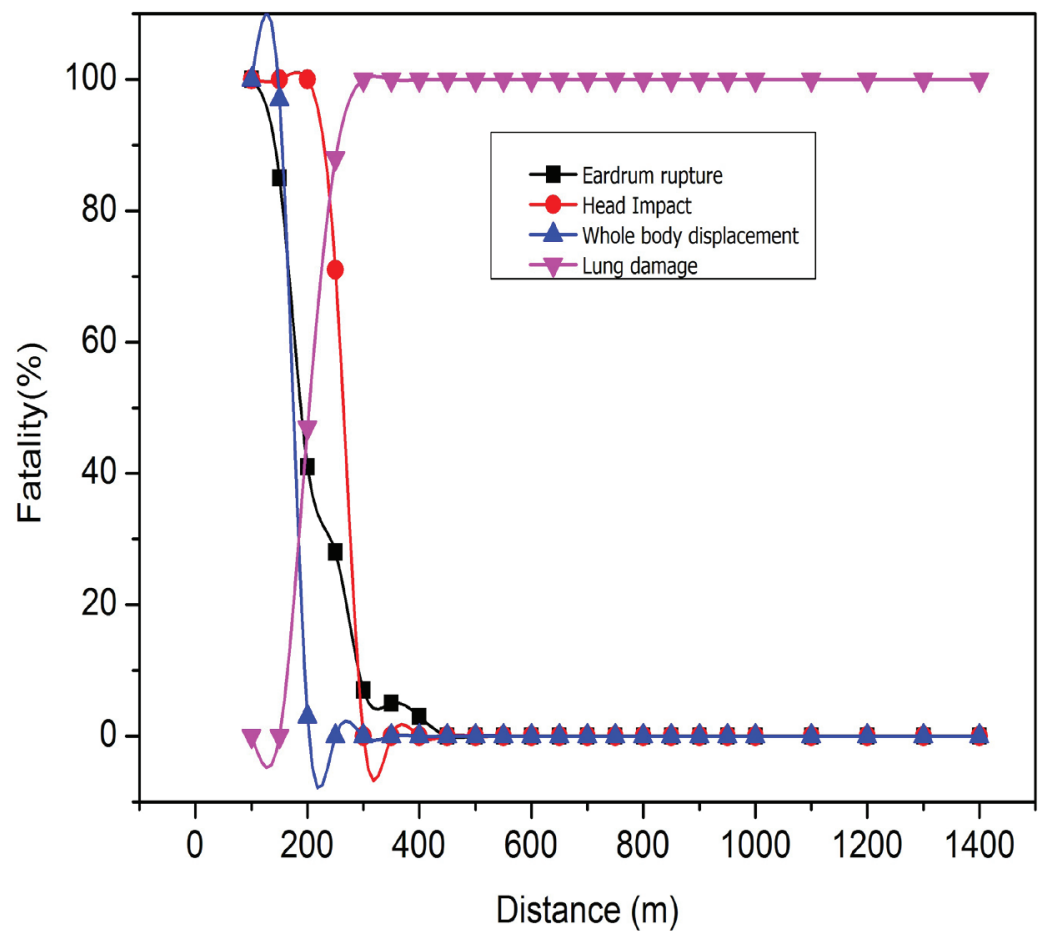

Fig. 4: Vulnerability of persons

\section{Conclusion}

The consequence analysis of UVCE resulting from the accidental release of 54 tonne of jet fuel in the vicinity of NPP is presented. The three empirical methods for explosion assessments (TNT, TNO multi energy and BST) were used to compute explosion overpressure as a function of scaled distance. At a distance of $1300 \mathrm{~km}$, the Ps values for the TNT, TNO and BST were 0.022 bar, 0.050 bar, and 0.050 bar respectively. These values are within the range causing window breakage and minor structural damage. Taking 
into account our scenario, some common conclusions drawn from this study are summarised as follows:

(i) The structural components within the bounds of the plant complex are vulnerable to major damage when fuels of 54 tonne is released causing vapour cloud explosion.

(ii) The minimum safety distance from the containment should not be less than 1 $\mathrm{km}$ where probability of major structural damage is less than $3 \%$. The minimum safety distance can go as higher as $2 \mathrm{~km}$ if a worst scenario is assumed (i.e. explosion of over 90 tonne).

(iii) The magnitude of explosion overpressure generated from the incident may not likely caused the collapse of reactor containment due to its robust civil engineering design. However, other structural components within the radial distance of $800 \mathrm{~m}$ may severely be affected. Further analyses using CFD models are needed to establish the limiting overpressure value that can lead to collapse.

The authors wishes to thank the Ministry of Higher Education Malaysia (MOHE) and Universiti Teknologi Malaysia (UTM) for providing research grants (Q.J130000.2546.14H41 and QJ130000 $254203 \mathrm{H} 41)$ for this work. Aminu Ismaila would like to acknowledge the financial support of Ahmadu Bello University, Zaria through the TetFund intervention scheme.

\section{References}

1. N. Siu, and G. Apostolakis, A methodology for analyzing the detection and suppression of fires in nuclear power plants. Nucl. Sci. Eng. J., 94:3 (1986).

2. Berg H.P. and Hauschild J., Probabilistic Assessment of Nuclear Power Plant Protection Against External Explosions. Nuclear Power-Practical Aspects. (2012).

3. J. Hauschild and H.-P. Berg, How to Assess External Explosion Pressure Wave. Elect. J. of Int. Group on Rel., 01:24 (2012).

4. S. J. Jeon, B. M Jin and Y. J. Kim. Assessment of the fire resistance of a nuclear power plant subjected to a large commercial aircraft crash. Nucl. Eng. and Design, 247:p1122 (2012).

5. HSE, A Review of the State-of-the-Art in Gas Explosion Modelling, H.S.L. C. J. Lea, Buxton. p. 80. (2002).

6. A. Ismaila, R.M. Kasmani and A.T. Ramli, Consequence Assessment of Vapour Cloud Explosion Involving Large Commercial Airliner Crash upon Nuclear Reactor Containment, Chem. Eng. Trans., 56, (2017) (to be published).

7. K.B. Mishra, K.D. Wehrstedt, and H. Krebs, Lessons learned from recent fuel storage fires. Fuel Proc. Tech., 107: p. 166-172 (2013).

8. F. Rigas, and S. Sklavounos, Risk and consequence analyses of hazardous chemicals in marshalling yards and warehouses at Ikonio/Piraeus harbour, Greece. J. of Loss Prev. in the Process Indus., 15(6): p. 531-544 (2002).

9. F.B.A. Beshara, Modelling of blast loading on aboveground structures-II. Internal blast and ground shock. Comp. \& Stru., 51(5): p. 597-606 (1994).

10. Baker, W.E., Cox, P. A., Westine, P. S.,. Kulesz, J. J. and Strehlow, R. A., Explosion Hazards and Evaluation. Elsevier (1983).

11. P.M. Locking, The Trouble with TNT Equivalence in 26th International Ballistics Symposium., Miami, FL. (2011). 
12. A.C. van den Berg, The multi-energy method: A framework for vapour cloud explosion blast prediction. J. of Hazard. Mat., 12(1): p. 1-10 (1985).

13. W.P.M. Mercx, A. C. van den Berg, C. J. Hayhurst, Developments in vapour cloud explosion blast modeling. J. of Hazardous Mater., 71(1-3) : p. 301-319 (2000).

14. J.A. Marc and E.K. Konstantinos, Fires, Explosions, and Toxic gas Dispersions: Effects calculation and Risk Analysis, United States: CRC Press, Taylor and Francis Group, Boca Raton,. 352 (2010).

15. A.R. Soman and G. Sundararaj, Consequence Assessment of Vapour cloud Explosion Involving Hydrogen Release. Int. J. of Emerging Tech. and Advanced Eng., 2(11): p. 291-297 (2012).

16. IAEA, Design of Reactor Containment Systems for Nuclear Power Plants, International Atomic Energy Agency: Vienna (2004).

17. Lees, F. P. Loss Prevention in the Process Industries, 2nd Ed., ButterworthHeinemann, Boston MA, pages 7/64 and 17/249 (1996a).

18. Netherlands Organisation of Applied Scientific Research ["TNO],"Methods for the Determination of Possible Damage to People and Objects Resulting from Releases of Hazardous Materials", CPR 16E ("green book"), Chapter 3, "The Consequences of Explosion Effects on Humans", page 17 (1989).

19. Finney, D.I., PROBIT Analysis, London: Camebridge University Press, (1971).

20. IAEA, Site Evaluation for Nuclear Installations Safety Requirement, International Atomic Energy Agnecy: Vienna (2016).

21. V.J. Clancey, Diagonostic Features of Explosion Damage, in 6th International Meeting on Forensic Science. 1972: Edinburg, Scotland.

22. Kayes, P.J., Manual of Industrial Hazards Assessment Techniques. Technica. 1985, London.

23. Santamaría, J.M. and P. Braña, Risk analysis and reduction in the chemical process industry. 1998, London Blackie Academic \& Professional.

24. J.r.m. Taveau, The Buncefield Explosion: Were the Resulting Overpressures Really Unforeseeable? Process Safety Prog., 31(1): p. 55-71 (2012).

25. D.M. Johnson, The potential for vapour cloud explosions - Lessons from the Buncefield accident. J. of Loss Prev. in the Process Indust., 23(6): p. 921-927 (2010). 